\title{
Physical Properties of Biocontainers for Greenhouse Crops Production
}

\author{
Michael R. Evans ${ }^{1,4}$, Matt Taylor ${ }^{2}$, and Jeff Kuehny ${ }^{3}$
}

ADDITIONAL INDEX WORDS. pots, sustainability, water usage, decomposition, strength

Summary. The vertical dry strength of rice hull containers was the highest of all containers tested. Plastic containers and paper containers had similar vertical dry strengths. Containers composed of $80 \%$ cedar fiber and $20 \%$ peat (Fertil), composted dairy manure (Cowpot), and peat had lower dry vertical dry strengths than the aforementioned containers but had higher vertical dry strengths than those composed of bioplastic (OP47), coconut fiber, and rice straw. Rice hull containers and paper containers had the highest lateral dry strengths. Rice straw, Cowpot, and plastic containers had similar dry lateral strengths, which were significantly higher than those of OP47, Fertil, coconut fiber, and peat containers. Highest dry punch strengths occurred with traditional plastic and Cowpot containers, while the lowest dry punch strengths occurred with OP47, Fertil, coconut fiber, peat, and rice straw containers. Plastic, rice hull, and paper containers had the highest wet vertical and lateral strengths. Plastic containers had the highest wet punch strength, while Fertil, Cowpot, and peat containers had the lowest wet punch strengths. When saturated substrate was placed into containers and the substrate surface and drainage holes were sealed with wax, plastic, OP47, and rice hull containers had the lowest rates of water loss per unit of container surface area, while peat, Fertil, and rice straw containers had the highest rates of water loss per unit of container surface area. The amounts of water required to produce a geranium (Pelargonium $\times$ hortorum) crop were significantly higher and the average irrigation intervals were shorter for peat, Fertil, coconut fiber, Cowpot, and rice straw containers than for traditional plastic containers. The amounts of water required to produce a geranium crop and the average irrigation intervals were similar among plastic, rice hull, and OP47 containers. Algal and fungal coverage on the outside container walls averaged $47 \%$ and $26 \%$ for peat and Fertil containers, respectively, and was higher than for all other containers tested, which had $4 \%$ or less algal and fungal coverage. After 8 weeks in the field, Cowpot containers had decomposed $62 \%$ and $48 \%$ in the Pennsylvania and Louisiana locations, respectively. Peat, rice straw, and Fertil containers decomposed $32 \%, 28 \%$, and $24 \%$, respectively, in Pennsylvania, and $10 \%$, $9 \%$, and $2 \%$, respectively, in Louisiana. Coconut fiber containers had the lowest level of decomposition at $4 \%$ and $1.5 \%$ in Pennsylvania and Louisiana, respectively.

$\mathrm{M}$ ost greenhouse crops are grown in containers of various shapes and sizes. The container size is typically dictated by the target size of the plants being grown as well as the length of the production time. Petroleum-based plastics (plastic) have been the materials of

This project was supported by the Arkansas Division of Agriculture, by The Louisiana State University Agricultural Center, and by Longwood Gardens.

We gratefully acknowledge the assistance of Drew Lehrian.

The mention of trade names implies no endorsement of the products mentioned, nor criticism of similar products not mentioned.

${ }^{1}$ Professor, Department of Horticulture, University of Arkansas, Fayetteville, AR 72701

${ }^{2}$ Director of Research, Longwood Gardens, Kennett Square, PA 19348

${ }^{3}$ Professor, School of Plant, Environmental and Soil Sciences, Louisiana State University, Baton Rouge, LA 70803

${ }^{4}$ Corresponding author. E-mail: mrevans@uark.edu. choice for the manufacture of greenhouse crop containers because plastic containers are strong and can be formed to essentially any size, shape, or color. However, the extensive use of plastic containers has also resulted in a significant waste disposal problem for the greenhouse industry.

The Pennsylvania Department of Agriculture estimated that greenhouses and nurseries in the state used over 12 million pounds of rigid plastic per year for production containers (Abdullah, 2003). These containers were ultimately recycled or discarded by the greenhouse or the final consumer. Hurley (2008) reported that the typical greenhouse operation in California discarded over $3560 \mathrm{lb}$ of plastic trays, flats, and containers annually. As part of a New Jersey recycling program, 10 participating greenhouse operations produced $3,320 \mathrm{lb}$ of polystyrene containers and over $65,980 \mathrm{lb}$ of high-density polyethylene containers (New Jersey Department of Agriculture, 2007). In addition to the waste plastic discarded directly by the greenhouse operation, the final consumers must eventually remove plants from the plastic containers and are likewise left with plastic containers of which they must dispose.

As the greenhouse industry has become more focused on implementing best management practices that increase the sustainability of its operations, the amount of waste plastics generated by greenhouses has become a significant issue of interest. Although recycling of containers is an option in certain situations, reducing the use of plastic containers by increasing the use of biocontainers is one strategy that could reduce the amount of waste plastic generated by greenhouse operations.

Biocontainers are generally defined as containers that are not produced from petroleum and that degrade rapidly when planted into the field or when placed in a composting operation. Biocontainers can be further described as being plantable or compostable. Plantable biocontainers are those that are designed to be left intact on the root ball and planted into the field, landscape bed, or final container. They are designed to allow roots to grow through the container walls and to decompose after being planted into the field or final container. Compostable biocontainers are designed to be removed

\begin{tabular}{llll}
\hline $\begin{array}{l}\text { Units } \\
\begin{array}{l}\text { To convert U.S. } \\
\text { to SI, multiply by }\end{array}\end{array}$ & U.S. unit & SI unit & $\begin{array}{l}\text { To convert SI } \\
\text { to U.S., multiply by }\end{array}$ \\
\hline 29.5735 & $\mathrm{fl} \mathrm{oz}$ & $\mathrm{mL}$ & 0.0338 \\
2.54 & inch(es) & $\mathrm{cm}$ & 0.3937 \\
25.4 & inch $(\mathrm{es})$ & $\mathrm{mm}$ & 0.0394 \\
0.4536 & $\mathrm{lb}$ & $\mathrm{kg}$ & 2.2046 \\
4.3942 & $\mathrm{oz} / \mathrm{inch}^{2}$ & $\mathrm{~g} \cdot \mathrm{cm}^{-2}$ & 0.2276 \\
1 & $\mathrm{ppm}$ & $\mathrm{mg} \cdot \mathrm{L}^{-1}$ & 1 \\
$\left({ }^{\circ} \mathrm{F}-32\right) \div 1.8$ & ${ }^{\circ} \mathrm{F}$ & ${ }^{\circ} \mathrm{C}$ & $\left(1.8 \times{ }^{\circ} \mathrm{C}\right)+32$
\end{tabular}


before final planting, broken apart, and composted.

Numerous types of biocontainers have been developed (Evans and Hensley, 2004; Gayed, 1971; Lahde and Kinnonen, 1974; Mrazek, 1986), and they have typically been composed of peat, paper, coconut fiber, rice hulls, poultry feather fiber, rice straw, dairy manure, or other organic components. One of the most common plantable biocontainers is the peat container. Although referred to as peat containers or peat pots, they are typically made from a combination of peat and paper. Wood-pulp containers, often marketed as DOT containers (Bethel Organics, Arcadia, FL) or Fertil containers (Fertil International, Boulogne Billancourt, France), are made from $80 \%$ cedar wood fiber, $20 \%$ peat, and lime. Paper pulp containers are produced from paper pulp with a binder. Cowpots (CowPots Co., Brodheadsville, PA) is the commercial name for a container made from composted dairy manure with a binder. Strawpots (Ivey Acres, Baiting Hollow, NY) are made from $80 \%$ rice straw, $20 \%$ coconut fiber, and a binder, while coconut fiber containers are made from medium and long $\mathrm{CO}^{-}$ conut husk fibers and a binder. One type of compostable biocontainer is the rice hull container, which is marketed under a variety of trade names. These containers are made from ground rice hulls and a binder and are marketed in various shapes and sizes. Another compostable biocontainer is the OP47 container (Summit Plastic Co., Tallmadge, $\mathrm{OH})$ fabricated from a bioplastic.

Despite the introduction of different types of biocontainers, limited research has been published regarding the characteristics of biocontainers compared with traditional petroleumbased-plastic containers. Candido et al. (2008) evaluated poinsettia (Euphorbia pulcherrima) plant growth in bioplastic containers containing $0 \%$ to $20 \%$ unidentified compostable material and reported that a bioplastic container with $0 \%$ compostable material did not develop lesions and resulted in plants with similar growth characteristics as plants grown in traditional petroleum-based plastic containers. Minuto et al. (2007) evaluated a biocontainer referred to as Mater-bi pots (Plastral, Sydney, Australia) and found that plants grown in these containers were similar to those grown in traditional plastic containers.
Evans and Hensley (2004) evaluated peat containers and feather fiber containers compared with traditional plastic containers. They reported that bedding plants grown in the two biocontainers were similar to those grown in plastic containers. Evans and Karcher (2004) evaluated the physical properties of peat, feather fiber, and plastic containers. They reported that plants in the peat and feather fiber biocontainers required more frequent irrigations as well as more water to produce a marketable crop. They also evaluated dry and wet strength of plastic, peat, and feather fiber containers. The peat and feather fiber biocontainers had lower dry and wet strength than the plastic control. Additionally, the wet strength of both types of biocontainers was significantly less than the dry strength. Evans and Karcher (2004) also reported that peat and feather fiber biocontainers had significantly higher percentages of the container surface covered with algae and fungi than traditional plastic containers. Furthermore, the peat container had a higher percentage of the container surface area covered with algae $(56 \%)$ than the feather fiber container $(5 \%)$.

Despite the development of numerous types of biocontainers, limited research has been conducted to evaluate their physical properties compared with petroleum-based plastic containers. The objective of this research was to evaluate various physical properties of seven commercially available biocontainers compared with a similar traditional petroleum-based plastic container.

\section{Materials and methods}

COMPARISON OF DRY AND WET STRENGTH OF PLASTIC AND BIOCONTAINERS. The types of containers evaluated included 4 -inch plastic [ $9.5 \mathrm{~cm}$ top diameter, $7.0 \mathrm{~cm}$ bottom diameter, $8.0 \mathrm{~cm}$ height, $470 \mathrm{~mL}$ volume (Dillen Products, Middlefield, $\mathrm{OH})], 5$-inch plastic $[12.5 \mathrm{~cm}$ top diameter, $9.5 \mathrm{~cm}$ bottom diameter, $9 \mathrm{~cm}$ height, $760 \mathrm{~mL}$ volume (Dillen Products)], 5-inch OP47 $(12.5 \mathrm{~cm}$ top diameter, $9.5 \mathrm{~cm}$ bottom diameter, $9.25 \mathrm{~cm}$ height, $840 \mathrm{~mL}$ volume), 4 -inch Fertil $(9.75 \mathrm{~cm}$ top diameter, $6.25 \mathrm{~cm}$ bottom diameter, $10 \mathrm{~cm}$ height, $465 \mathrm{~mL}$ volume), 4-inch Cowpot $(9 \mathrm{~cm}$ top diameter, $6.5 \mathrm{~cm}$ bottom diameter, $9 \mathrm{~cm}$ height, $460 \mathrm{~mL}$ volume), 4 -inch coconut fiber $[10 \mathrm{~cm}$ top diameter, $6.5 \mathrm{~cm}$ bottom diameter, $8.5 \mathrm{~cm}$ height, $420 \mathrm{~mL}$ volume (ITML Horticultural Products, Brantford, ON, Canada)], 4-inch peat [9.5 $\mathrm{cm}$ top diameter, $6.5 \mathrm{~cm}$ bottom diameter, $9 \mathrm{~cm}$ height, $400 \mathrm{~mL}$ volume (Jiffy, Kristiansand, Norway)], 4 -inch rice hull containers $[9 \mathrm{~cm}$ top diameter, $7 \mathrm{~cm}$ bottom diameter, $8.75 \mathrm{~cm}$ height, $440 \mathrm{~mL}$ volume (Summit Plastic Co.)], 4-inch paper [10 $\mathrm{cm}$ top diameter, $7 \mathrm{~cm}$ bottom diameter, $10 \mathrm{~cm}$ height, $635 \mathrm{~mL}$ volume (Western Pulp Products, Corvallis, OR)], and 4-inch rice straw (10 $\mathrm{cm}$ top diameter, $7.5 \mathrm{~cm}$ bottom diameter, $13 \mathrm{~cm}$ height, $765 \mathrm{~mL}$ volume). The 4 -inch plastic container served as the control for all 4-inch biocontainers, while the 5 -inch plastic container served as the control for the OP47 container.

For determining dry strength, new, unused containers were tested. For wet strength, containers were filled with LCl root substrate (Sun Gro Horticulture, Bellevue, WA), placed in a glass-glazed greenhouse, and watered once per day for 4 weeks. Greenhouse air temperatures ranged from 20 and $28{ }^{\circ} \mathrm{C}$ and light levels ranged from 350 to $440 \mu \mathrm{mol} \cdot \mathrm{s}^{-1} \mathrm{~m}^{-2}$ at $1200 \mathrm{HR}$. After 4 weeks, root substrate was removed from the containers and the container strength was tested.

Strength was tested by subjecting containers to increasing amounts of pressure using a TAXT 21 Texture Analyzer (Texture Technologies, Scarsdale, NY). The pressure required (maximum force as kilograms) to crush containers vertically (top to bottom with container set upright) for $30 \mathrm{~mm}$ and laterally (container lying on side with weight placed on the bottom edge of the container) for $50 \mathrm{~mm}$ was determined. Container wall strength was also examined by determining the amount of pressure required to punch through the container wall with a 5$\mathrm{mm}$ ball probe. For all strength tests, a crosshead speed of $10 \mathrm{~mm} \cdot \mathrm{s}^{-1}$ was employed. For dry and wet strength and for each of the types of strength tests, eight replications were conducted with a container serving as a replication. An analysis of variance (ANOVA) was conducted to determine if significant differences in container strength occurred among containers. Where significant differences occurred, a least significant difference (LSD) mean separation 
test $(\alpha=0.05)$ was conducted to determine significant differences between specific means.

COMPARISON OF WATER USAGE IN PLASTIC AND BIOCONTAINERS. Six-leaf plugs (\#277 plug trays) of 'Orbit Cardinal' geranium were transplanted into the containers that had been filled with 400 or $740 \mathrm{~mL}$ of LCl root substrate for the 4 -inch and 5 -inch containers, respectively. Additionally, because of their larger volumes, paper and straw containers were also filled with $700 \mathrm{~mL}$ of substrate. This allowed an evaluation of these containers with an amount of substrate consistent with the other 4 -inch containers, as well as with a volume of substrate with which they would be filled in a commercial situation. Containers with plants were placed on drainage trays in a glass-glazed greenhouse. Environmental conditions were as described for Expt. 1 .

Plants were initially irrigated with a $200 \mathrm{~mL}$ of solution containing 200 $\mathrm{mg} \cdot \mathrm{L}^{-1}$ nitrogen using a $15 \mathrm{~N}-2.2 \mathrm{P}-$ $12.5 \mathrm{~K}$ water-soluble fertilizer (Excel 15-5-15 Cal Mag®; Scotts, Marysville, $\mathrm{OH})$. Afterward, each container was irrigated with $150 \mathrm{~mL}$ of solution as the surface of the substrate began to dry as determined visually. Drainage after irrigation was collected in the drainage trays, measured, and recorded.

The total water used by the crop during the production cycle (water retained in the container) and the average irrigation interval (required frequency of irrigation) was determined. The experiment was ended after 8 weeks. The experimental design was a complete randomized block with eight blocks and each container type appearing once per block with a container serving as an experimental unit. An ANOVA was conducted to determine if significant differences occurred among the container types. Where significant differences occurred, an LSD mean separation test $(\alpha=0.05)$ was conducted to determine individual differences between means.

Additionally, containers were filled to the container rim with LCl root substrate. The substrate was top watered to saturation and allowed to drain to attain container capacity. Water was applied in a way to not saturate the container walls. After drainage ceased, the drainage holes of the containers and the root substrate surface were sealed with paraffin wax (Fisher Scientific, Fair
Lawn, NJ). The containers were weighed and placed in a glass-glazed greenhouse. Environmental conditions were as described for Expt. 1. Containers were weighed at 24-h intervals for $7 \mathrm{~d}$ to determine water loss through the container walls. Because small differences in container dimensions existed, water loss was expressed on the basis of grams per square centimeter of container surface area. The experimental design was a complete randomized design with five replications of each container. The cumulative water loss was regressed against time to develop models that described the rate of water loss through the container walls over a $7-\mathrm{d}$ period.

Comparison OF ALgal AND FUNGAL GROWTH ON PLASTIC AND BIOCONTAINERS. Containers were filled with LCl root substrate to within $1 \mathrm{~cm}$ of the rim of the containers. All 4-inch containers were placed potto-pot in $53 \times 27 \times 6$-cm plastic trays (Dillen Products). The OP47 and 5inch plastic containers were placed in special trays designed specifically for the OP47 container. All trays with containers were placed in a greenhouse on expanded metal benches and under environmental conditions as described for Expt. 1. Plants were overhead irrigated with a solution containing $100 \mathrm{mg} \cdot \mathrm{L}^{-1}$ nitrogen using a $15 \mathrm{~N}-2.2 \mathrm{P}-12.5 \mathrm{~K}$ water-soluble fertilizer (Excel 15-5-15 Cal Mag®; Scotts) when the root substrate surface of $\approx 25 \%$ of the containers in a tray were dry as determined visually. After 6 weeks, substrate was removed from the containers. Containers were dried and dissected into fractions that were discolored or not discolored with fungal or algal growth. The total container surface area and the discolored portion of the container were determined using an area meter (LI3000; LI-COR, Lincoln, NE). The container surface area discolored with algae or fungi was expressed as a percentage of the total surface area.

The experimental design was a complete randomized block with four blocks. A container served as a subsample and a tray served as an experimental unit. An ANOVA was conducted to determine if significant differences occurred among the container types. Where significant differences occurred, an LSD mean separation test $(\alpha=0.05)$ was conducted to determine individual differences between means.
Comparison OF PLANTABLE BIOCONTAINER DECOMPOSITION UNDER FIELD CONDITIONS. Six-leaf plugs of 'Cooler Blush' vinca (Catharanthus roseus) were transplanted into the peat, Fertil, coconut fiber, rice straw, and Cowpot containers filled with LCl root substrate. Evaluation was restricted to these containers because they were marketed as being plantable biocontainers. Evaluations were conducted in Baton Rouge, LA, and Kennett Square, PA. Plants were placed into glass-glazed greenhouses and were allowed to grow for 5 weeks in Louisiana and 7 weeks in Pennsylvania following standard cultural conditions, and then plants were transplanted into out-of-doors plant beds. Greenhouse production times were different for the two locations due to differences in plant growth rates. In Louisiana, the soil was an Olivier silt loam amended with composted bark with a $\mathrm{pH}$ of 6.5. In Pennsylvania, the soil was a clay-loam with a $\mathrm{pH}$ of 6.7. All biocontainers were left intact and planted into the field. Plants were not fertilized. After 8 weeks, the containers were dug, cleaned, and dried. The level of decomposition of the container was determined and expressed as a percentage of the original dry weight of the unused container.

The experimental design was a complete randomized block with four blocks and each container type appearing once per block. An ANOVA was conducted to determine if significant differences occurred among the container types. Where significant differences occurred, an LSD mean separation test $(\alpha=0.05)$ was conducted to determine individual differences between means.

\section{Results and discussion}

COMPARISON OF DRY AND WET STRENGTH OF PLASTIC AND BIOCONTAINERS. Rice hull containers had the highest dry vertical strength that was higher than that of paper and plastic containers, which had similar dry vertical strengths (Fig. 1). Fertil, Cowpot, and peat containers had lower dry vertical strengths than the plastic controls, but they had higher dry vertical strengths than OP47, coconut fiber, and rice straw containers, which had the lowest dry vertical strengths of all containers evaluated. Rice hull and paper containers had the highest dry lateral strengths followed by plastic and 
Cowpot containers. The lowest dry lateral strengths occurred for the OP47, Fertil, coconut fiber, peat, and rice straw containers. Plastic containers had the highest dry punch strength. Coconut fiber, rice hull, and paper containers had higher dry punch strengths than OP47, Fertil, Cowpot, peat, and rice straw containers, which had the lowest dry punch strengths.

Plastic and paper containers had higher wet vertical strengths than all other containers (Fig. 2). Rice hull containers had higher wet vertical strength than OP47, Fertil, Cowpot, coconut fiber, peat, and rice straw containers. Rice hull containers had a higher wet lateral strength than all other containers evaluated. Plastic and paper containers had similar wet lateral strengths, which were higher than those of OP47, Cowpot, coconut fiber, peat, and rice straw containers, with the later having similar wet lateral strengths. Plastic containers had higher wet punch strengths than all other

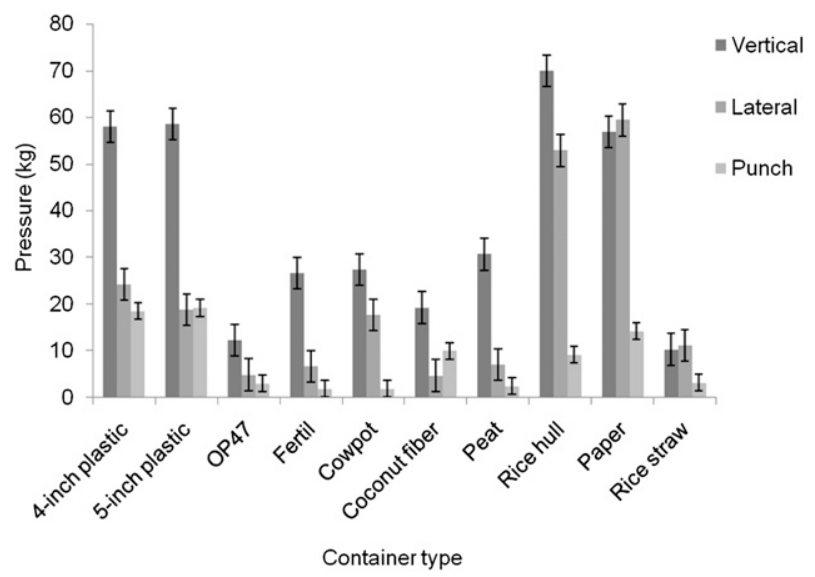

Fig. 1. Dry vertical, lateral, and punch strength of plastic containers and various biocontainers. Vertical strength was tested with pressure applied to the top of the container and lateral strength was tested with pressure applied to the side of the container. Punch strength was tested by forcing a $5-\mathrm{mm}(0.2 \mathrm{inch})$ ball probe through the container wall. Error bars represent \pm least significant difference value $(\alpha=0.05)$ for each strength test; OP47 (Summit Plastic Co., Tallmadge, OH), Fertil (Fertil International, Boulogne Billancourt, France), Cowpot (CowPots Co., Brodheadsville, PA); $1 \mathrm{~kg}=2.2046 \mathrm{lb}, 1$ inch $=2.54 \mathrm{~cm}$.

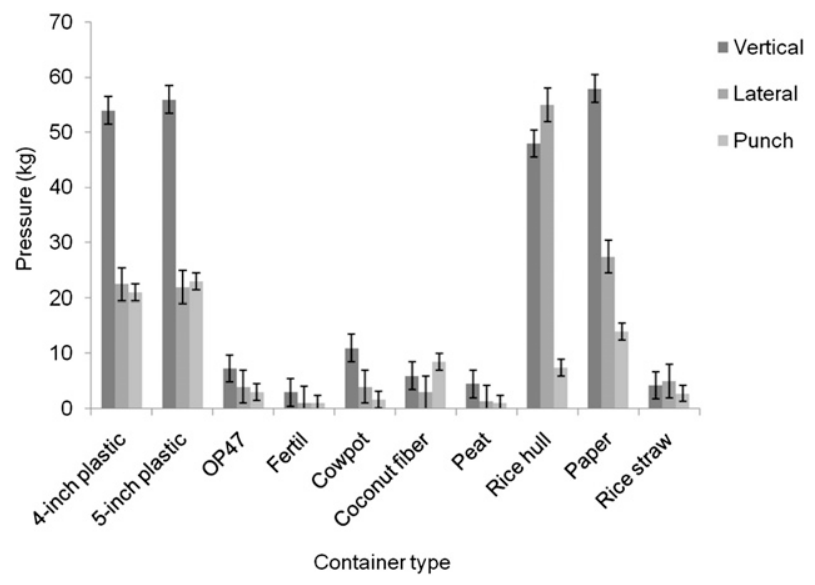

Fig. 2. Wet vertical, lateral, and punch strength of plastic containers and various biocontainers 4 weeks after being filled with wet substrate in a greenhouse environment. Vertical strength was tested with pressure applied to the top of the container and lateral strength was tested with pressure applied to the side of the container. Punch strength was tested by forcing a $5-\mathrm{mm}$ ball probe through the container wall. Error bars represent \pm least significant difference value $(\alpha=0.05)$ for each strength type; OP47 (Summit Plastic Co., Tallmadge, OH), Fertil (Fertil International, Boulogne Billancourt, France), Cowpot (CowPots Co., Brodheadsville, PA); $1 \mathrm{~kg}=2.2046 \mathrm{lb}, 1$ inch $=2.54 \mathrm{~cm}$.

containers evaluated. Paper containers had higher wet punch strength than all containers except plastic containers, and coconut fiber containers had higher wet punch strength than all containers except plastic and paper containers. The lowest wet punch strengths occurred for OP47, Fertil, Cowpot, peat, and rice straw containers.

Dry vertical and lateral strengths were primarily a function of container wall rigidity and thickness. Containers such as OP47 that had thinner and more flexible walls had lower dry vertical and lateral strengths than containers with thicker and more rigid walls such as rice hull containers. Dry punch strength was affected by wall thickness as well as whether there were physical openings in the container walls. Containers such as OP47 with a thin wall and rice straw containers that had physical openings in the container walls had the lowest dry punch strengths.

Wet strength decreased for all containers that were able to absorb water into the container wall. As was the case with peat and feather fiber containers (Evans and Karcher, 2004), the absorption of water by the container walls resulted in a softening of the container wall and a subsequent reduction in all measures of strength. Because additional wet lateral strength would ultimately be provided to the containers by filling them with substrate, wet vertical and punch strengths were the most important strength measures, as these two variables were a measure of the handability of a wet container. Although container wet vertical and punch strengths varied among the containers, the most important issue was whether a container possessed enough strength when wet to be packaged, shipped, and handled by consumers. Although no specific standards or recommendations have been developed to date for biocontainers, the authors found that a container required a minimum of $2 \mathrm{~kg}$ wet vertical and punch strength. If the strength was less than $2 \mathrm{~kg}$, the containers tended to tear or break, and handling became problematic. In this study, all containers had adequate wet vertical and punch strengths with the exception of Fertil, peat, and Cowpot containers, and thus handling of these containers when wet was difficult and would make these containers problematic for greenhouse crop producers. 
COMPARISON OF WATER USAGE IN PLASTIC AND BIOCONTAINERS. More water was required to grow a geranium to a marketable stage in 4 -inch peat, Fertil, coconut fiber, paper, rice straw, and Cowpot containers than when grown in 4-inch plastic containers (Fig. 3). When the volume of substrate was increased in the rice straw and paper containers, the amount of water required increased. A similar amount of water was required to grow geranium to a marketable stage in rice hull containers compared with plastic. The amount of water required to grow a geranium crop was not different between the OP47 and the 5 -inch plastic container, which required 3210 and $3120 \mathrm{~mL}$, respectively (data not shown).

The average irrigation interval for all 4-inch biocontainers except rice hull containers was lower than that of 4-inch plastic container (Fig. 4 ). Rice hull containers had a similar irrigation interval as the $10.0-\mathrm{cm}$ plastic container. The average irrigation interval was similar for OP47 and the 5 -inch plastic containers, which were 4.4 and $4.5 \mathrm{~d}$, respectively (data not shown).

For the plastic, OP47, rice hull, and paper containers, a linear model best described the cumulative water

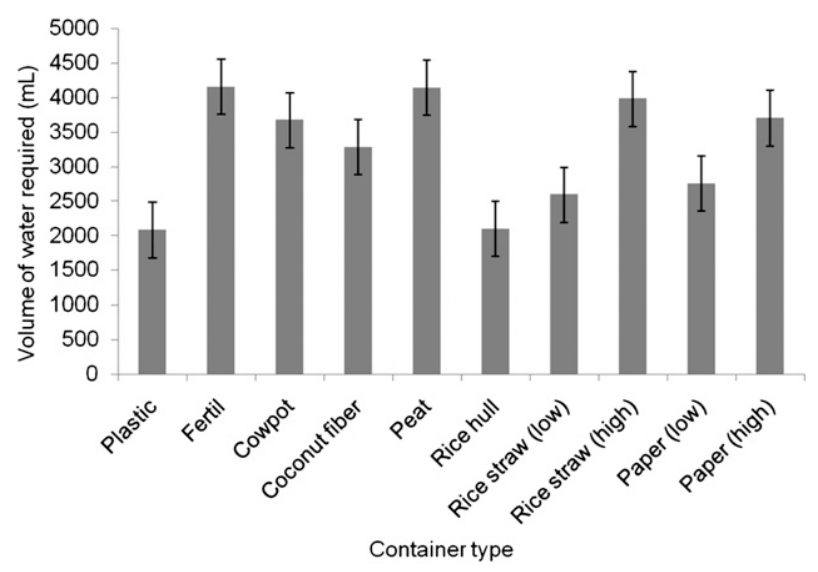

Fig. 3. Volume of water required to produce a marketable geranium in a 4-inch $(10.2 \mathrm{~cm})$ plastic container and various 4 -inch biocontainers. All containers were filled with $400 \mathrm{~mL}$ of substrate except for "rice straw (high)" and "paper (high)" containers, which were filled with $700 \mathrm{~mL}$ of substrate. Error bars represent \pm least significant difference value $(\alpha=0.05)$; Fertil (Fertil International, Boulogne Billancourt, France), Cowpot (CowPots Co., Brodheadsville, PA); $1 \mathrm{~mL}=$ $0.0338 \mathrm{fl} \mathrm{oz}$.

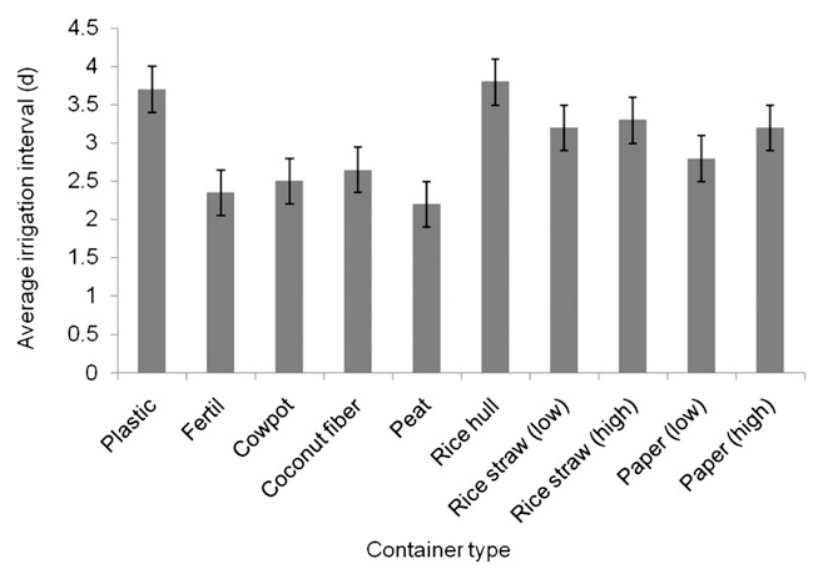

Fig. 4. Average irrigation interval for geranium grown in a 4-inch $(10.2 \mathrm{~cm})$ plastic container and various 4 -inch biocontainers. All containers will filled with $400 \mathrm{~mL}$ of substrate except for "rice straw (high)" and "paper (high)" containers, which were filled with $700 \mathrm{~mL}$ of substrate. Error bars represent \pm least significant difference value $(\alpha=0.05)$; Fertil (Fertil International, Boulogne Billancourt, France), Cowpot (CowPots Co., Brodheadsville, PA); $1 \mathrm{~mL}=$ $0.0338 \mathrm{fl} \mathrm{oz}$.

loss rate over $7 \mathrm{~d}$ (Fig. 5). However, a hyperbolic growth function was the best model describing the rate of water loss through the container walls of Fertil, peat, rice straw, coconut fiber, and Cowpot containers. This model was $\mathrm{y}=[(\max \times$ days $) /(\mathrm{K}+$ days)] where y was cumulative water loss, max was the asymptotic maximum water loss for each container, days was the number of days following saturation, and $\mathrm{K}$ was the number of days at which one half maximum water loss was reached. Containers tended to segregate into three groups with respect to water loss rates through the container walls. Plastic, rice hull, and OP47 containers had the lowest rates of water loss, while rice straw, coconut fiber, Fertil, and peat containers had the highest rates of water loss. Cowpot and paper containers had water loss rates that were between these two groups of containers.

Although differences in plant growth as well as substrate surface area may have affected the amount of water required to grow a crop as well as the average irrigation interval, the rate of water loss through the container wall was also a major factor affecting these two variables. Those containers that had the highest rate of water loss through the container walls also had the highest water requirement and the lowest irrigation interval. Containers such as rice hull and OP47 containers that were relatively impermeable to water and had a similar water loss rate as their plastic controls had similar water requirements and irrigation intervals. These results are consistent with those of Evans and Hensley (2004) who reported that plants grown in peat and feather fiber containers required more water than those grown in plastic, and that peat and feather fiber containers allowed water to evaporate through their container walls at a faster rate than plastic containers. This could also explain why the amount of water required to produce a geranium crop increased in paper and straw containers as the substrate volume increased because, with the higher volume of substrate, more substrate was placed in contact with the container wall, resulting in a higher rate of evaporation. Because water requirement may increase significantly with the use of certain biocontainers, the benefits of reducing waste plastic 


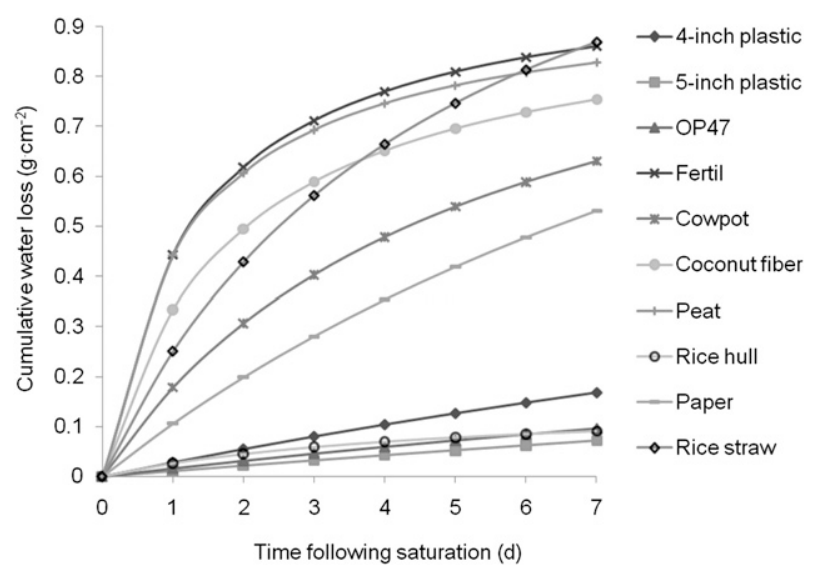

Fig. 5. Cumulative water loss as milliliters per square centimeter of container surface area over a $7-\mathrm{d}$ period for traditional plastic and various biocontainers. The equations for each container type were: 4 -inch $(10.2 \mathrm{~cm})$ plastic, $\mathrm{y}=0+0.025 \mathrm{x}$, $\left(\mathrm{R}^{2}=0.98\right) ; 5$-inch $(12.7 \mathrm{~cm})$ plastic, $\mathrm{y}=0+0.011 \mathrm{x},\left(\mathrm{R}^{2}=0.97\right) ;$ OP47 (Summit Plastic Co., Tallmadge, $\mathrm{OH}), \mathrm{y}=0+0.014 \mathrm{x},\left(\mathrm{R}^{2}=0.96\right)$; Fertil (Fertil International, Boulogne Billancourt, France $), y=[(1.02 x) /(1.302+x)], R^{2}=0.98$; Cowpot (CowPots Co., Brodheadsville, PA), $\mathrm{y}=\left[(1.093 \mathrm{x}) /(5.129+\mathrm{x}), \mathrm{R}^{2}=0.97\right.$; coconut fiber, $\mathrm{y}=[(0.9542 \mathrm{x}) /(1.859+\mathrm{x})] ; \mathrm{R}^{2}=0.98 ;$ peat, $\mathrm{y}=[(0.9692 \mathrm{x}) /(1.196+$ $\mathrm{x})], \mathrm{R}^{2}=0.98$; rice hull, $\mathrm{y}=0+0.014 \mathrm{x},\left(\mathrm{R}^{2}=0.93\right)$; paper, $\mathrm{y}=0+0.075 \mathrm{x}$ $\left(R^{2}=0.98\right) ;$ straw, $y=[(1.475 x) /(4.877 x)], R^{2}=0.99 ; 1 \mathrm{~g} \cdot \mathrm{cm}^{-2}=0.2276 \mathrm{oz} / \mathrm{inch}^{2}$.

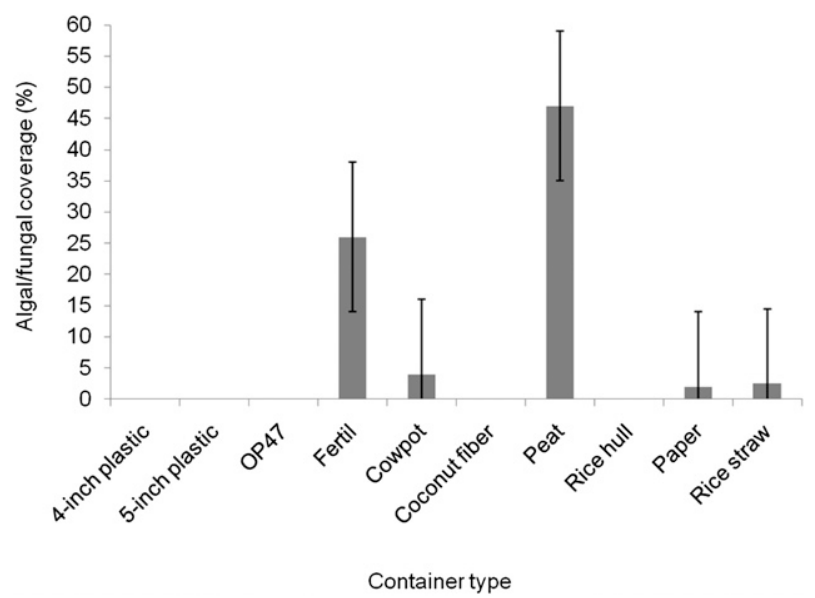

Fig. 6. Algal and fungal growth on container outer wall surface as a percentage of total container surface area after 6 weeks in a greenhouse environment. Error bars represent \pm least significant difference value $(\alpha=0.05)$ for each container type; OP47 (Summit Plastic Co., Tallmadge, OH), Fertil (Fertil International, Boulogne Billancourt, France), Cowpot (CowPots Co., Brodheadsville, PA); 1 inch $=2.54 \mathrm{~cm}$.

would need to be weighed against the increased water usage. Where water use or availability is a major consideration, biocontainers such as OP47 or rice hulls may be preferred to other biocontainers that have a higher water usage requirement.

COMPARISON OF ALGAL AND FUNGAL GROWTH ON PLASTIC AND BIOCONTAINERs. After 6 weeks, there was no visually apparent algal or fungal growth on the container walls of the coconut fiber, rice hull, OP47, or plastic containers (Fig. 6). Cowpot, paper, and rice straw containers had $2 \%$ to $4 \%$ of their container walls covered with fungal or algal growth and were not different from one another. At $26 \%$ and $47 \%$, respectively, Fertil and peat containers had the highest proportion of their surface covered with algal or fungal growth. Evans and Karcher (2004) also reported that peat containers had a high level of algal/fungal growth on the container walls. This was attributed to the difference in the water absorption by the container walls as well as to the container wall chemistry. These differences may also have been the reason for differences observed in this study. Biocontainers with no visible algal/ fungal growth, such as OP47, rice hull, and coconut fiber containers, tended to be impermeable to water or dried quickly after irrigation and were composed of materials resistant to decomposition such as coconut fiber.

Comparison of plantable BIOCONTAINER DECOMPOSITION UNDER FIELD CONDITIONS. In Louisiana and Pennsylvania, Cowpot containers had the highest level of decomposition after 8 weeks in the field (Fig. 7). Although lower than Cowpot containers, peat, rice straw, and Fertil containers had a higher level of decomposition than coconut fiber containers, which had the lowest level of decomposition of all the containers evaluated. Differences in decomposition rates may be at least partially due to the composition of the containers. Those containers composed of materials high in cellulose such as Cowpots had higher rates of decomposition than those composed of materials high in lignin or other difficult-to-decompose components such as coconut fiber containers. Furthermore, the significant level of nitrogen present in the dairy manure used to formulate the Cowpot containers may have increased microbial activity and subsequent decomposition of the containers. Decomposition levels were higher in Pennsylvania than in Louisiana. This may have been due to the longer greenhouse production time of 7 weeks in Pennsylvania compared with 5 weeks in Louisiana. In addition to the longer time in the greenhouse environment in Pennsylvania, larger plants with larger root systems may have facilitated a more rapid decomposition rate. Although all of the containers evaluated were marketed as plantable biocontainers, not all decomposed rapidly. In cases such as coconut fiber containers, the rate of container decomposition may be slow enough that the containers do not significantly decompose and when locations are replanted, previously planted containers may need to manually broken apart and incorporated into the soil or removed before replanting.

\section{Conclusions}

Physical properties varied among the different types of biocontainers 


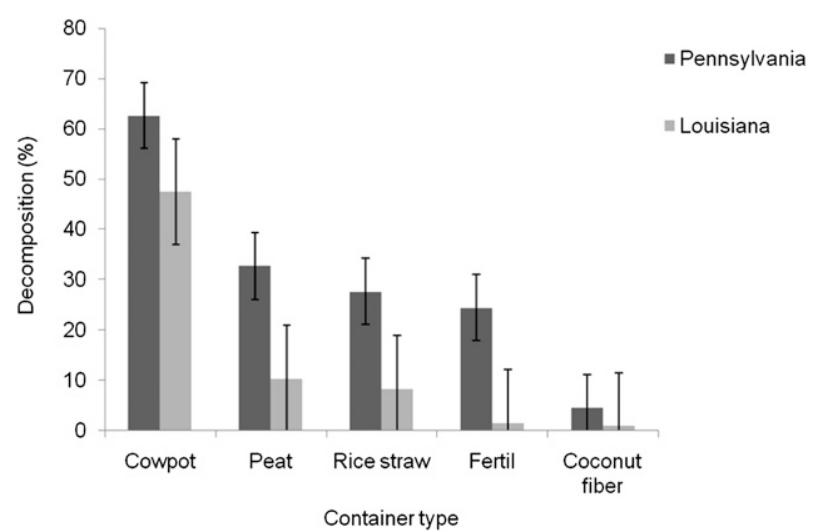

Fig. 7. Decomposition as a percentage of unused container weight after 8 weeks planted out-of-doors in plant beds in Baton Rouge, LA, and Kennett Square, PA. Error bars represent \pm least significant difference value $(\alpha=0.05)$; Cowpot (CowPots Co., Brodheadsville, PA), Fertil (Fertil International, Boulogne Billancourt, France); 1 inch $=2.54 \mathrm{~cm}$.

and were different from those of traditional plastic containers. Of greatest significance was container wet strength and water requirements. Fertil, peat, and Cowpot containers had wet strengths low enough to make handling difficult. All biocontainers except rice hull and OP47 containers allowed water to evaporate through their container walls and had higher water usage than traditional plastic containers. Depending upon the specific location, crop, and cultural conditions, different container physical properties will be more or less important. Because the differences in physical properties of biocontainers compared with plastic containers were specific for each type of biocontainer, greenhouse managers wanting to use biocontainers will need to decide which of the physical properties are most important and select biocontainers with physical properties that best match their needs.

\section{Literature cited}

Abdullah, G. 2003. Making the most of a powerful nuisance. Penn State Agr. Mag. 2003(Fall):17-18.

Candido, V., D. Castronuovo, C. Manera, and V. Miccolis. 2008. Poinsettia (Euphorbia pulcherrima) cultivation in biodegradable pots: Mechanical and agronomical behavior of pots and plant traits. Acta Hort. 801:1563-1570.

Evans, M.R. and D. Hensley. 2004. Plant growth in plastic, peat and processed poultry feather fiber growing containers. HortScience 39:1012-1014.

Evans, M.R. and D. Karcher. 2004. Properties of plastic, peat and processed poultry feather growing containers. HortScience 39:1008-1011.

Gayed, S.K. 1971. Effect of transplanting tobacco seedlings in peat pots on plant vigor and on susceptibility to Thielaviopsis root rot. Can. Plant Dis. Surv. 51(4):142144.

Hurley, S. 2008. Postconsumer agricultural plastic report. 2 Feb. 2010. <http:// www.ciwmb.ca.gov/publications/Plastics/ 2008019.pdf>.

Lahde, E. and K. Kinnonen. 1974. The relationship between wall strength of paper and peat pots and the initial development of seedlings in northern Finland. Folia Forestalia 197:1-19.

Minuto, G., A. Minuto, L. Pisi, F. Tinivella, S. Guerrini, M. Capurro, and I. Amprimo. 2007. Use of compostable pots for potted ornamental plant production. Acta Hort. 801:367-372.

Mrazek, F. 1986. Comparative growth studies of plants in peat pots and with naked roots in an advanced plantation of douglas firs. Beitrage fur die Forstwirtschaft 20(3):128-129.

New Jersey Department of Agriculture. 2007. New Jersey agricultural plastics recycling program enters eleventh year. 2 Feb. 2010. <http://www.state.nj.us/ agriculture/news/press/2007/approved/ press070426.html>. 